\title{
Initiating activities of daily living contributes to well-being in people with dementia and their carers
}

DOI:

10.1002/gps. 4728

\section{Document Version}

Final published version

Link to publication record in Manchester Research Explorer

\section{Citation for published version (APA):}

Giebel, C., \& Sutcliffe, C. (2017). Initiating activities of daily living contributes to well-being in people with dementia and their carers. International journal of geriatric psychiatry. https://doi.org/10.1002/gps.4728

\section{Published in:}

International journal of geriatric psychiatry

\section{Citing this paper}

Please note that where the full-text provided on Manchester Research Explorer is the Author Accepted Manuscript or Proof version this may differ from the final Published version. If citing, it is advised that you check and use the publisher's definitive version.

\section{General rights}

Copyright and moral rights for the publications made accessible in the Research Explorer are retained by the authors and/or other copyright owners and it is a condition of accessing publications that users recognise and abide by the legal requirements associated with these rights.

\section{Takedown policy}

If you believe that this document breaches copyright please refer to the University of Manchester's Takedown Procedures [http://man.ac.uk/04Y6Bo] or contact uml.scholarlycommunications@manchester.ac.uk providing relevant details, so we can investigate your claim.

\section{OPEN ACCESS}




\title{
Initiating activities of daily living contributes to well-being in people with dementia and their carers
}

\author{
Clarissa M. Giebel ${ }^{1,2}$ (D) and Caroline Sutcliffe ${ }^{3}$ \\ ${ }^{1}$ School of Health Sciences, University of East Anglia, Norwich, UK \\ ${ }^{2}$ Division of Neuroscience and Experimental Psychology, University of Manchester, Manchester, UK \\ ${ }^{3}$ Personal Social Services Research Unit, The University of Manchester, Manchester, UK \\ Correspondence to: C. Giebel, E-mail: c.giebel@uea.ac.uk
}

\begin{abstract}
Objective: Problems with everyday functioning are linked to reduced well-being in people with dementia $(\mathrm{PwD})$ and their carers. However, previous research has almost solely investigated the performance of everyday activities, and global functioning without analysing individual activities. This study explored how deficits in initiating and performing individual activities were associated with carer burden and poorer quality of life of carers and PwD.

Methods: Carers of people with mild dementia were recruited via 10 National Health Service Trusts, as well as through attending six carer support groups. Carers were asked to complete the revised Interview for Deteriorations in Daily Living Activities in Dementia 2 (R-IDDD2), and measures on carer burden, well-being, and person with dementia well-being. Data were analysed using correlation analysis.

Results: Two hundred and seventy-two carers completed the R-IDDD2. Carers were grouped into those with low or high ratings of well-being based on the mean scores. All but three activities on the initiative and/or performance scale were significantly associated with carer burden and carer and PwD quality of life. Engaging in hobbies and maintaining an active social life were most strongly associated with carer and PwD well-being. Initiating computer use, driving, and medication management were not related to carer burden.

Conclusions: Findings from this study can have direct implications for improving care management early in the disease. Post-diagnostic support needs to provide more opportunities for PwD, and their carers, to engage in social groups, whilst interventions targeted at living well with dementia need to particularly improve the initiative of engaging in individual hobbies. (C) 2017 The Authors. International Journal of Geriatric Psychiatry published by John Wiley \& Sons Ltd.
\end{abstract}

Key words: Dementia; activities of daily living; carers; quality of life History: Received 14 November 2016; Accepted 30 March 2017; Published online in Wiley Online Library (wileyonlinelibrary. com)

DOI: $10.1002 /$ gps.4728

\section{Introduction}

Living well with dementia is important once a diagnosis has been made. With an estimated 46 million cases worldwide (Alzheimer's Disease International, 2015), there is a much larger number of people who are affected by the condition: carers and other family members. Symptoms of dementia therefore not only affect the quality of life (QoL) of the person with dementia (PwD) (Beerens et al., 2013; Orgeta et al., 2015), including aspects of the person's physical, social, and psychological life (Birren et al., 1991), but also the QoL and stress that informal carers, and thus family members, might experience (Mioshi et al., 2013; Sutcliffe et al., 2016).

Unpaid family carers carry the greatest care burden in dementia (Prince et al., 2014). As the disease progresses, carers have an increasing level of caring responsibilities, and depending on their coping strategies, this can have a negative impact on their burden and QoL (Mioshi et al., 2013; Sutcliffe et al., 2016). Depending on the symptom severity, family carers can become unable to cope with the symptoms on their own and need to engage paid carers, or decide 
for the PwD to transition into a care home (Toot et al., 2017). In order to delay care home placement and prolong living at home, carers' levels of well-being need to be maintained at high levels.

One primary symptom of dementia that is found to impact on the QoL is everyday functioning (Andersen et al., 2004; Beerens et al., 2016; Giebel et al., 2016a). From the early stages of dementia onwards, people are found to struggle in performing complex instrumental activities of daily living (IADLs), such as using the telephone, and also maintaining more basic ADLs, such as continence (Monaci and Morris, 2012; Bier et al., 2013; Giebel et al., 2017a). In a large European analysis of community-dwelling PwD at the transition point into long-term care, deficits in ADLs were found to contribute to increased carer burden (Sutcliffe et al., 2016) and to reduced PwD QoL (Beerens et al., 2016), which is corroborated in other studies (Fauth et al., 2016). However, how individual daily activities are related to well-being has received little attention to date. Difficulties in maintaining a social life and following current affairs were found to be linked to reduced well-being in both carers and PwD (Giebel et al., 2016a). Exploring the overall association between everyday functioning and wellbeing offers little insights into this relationship. In order to help PwD and their carers on an individual basis, research needs to explore which individual activities have an effect on well-being.

One area of everyday functioning that has been little explored however, in itself and in relation to well-being, is initiating everyday activities. The majority of research solely focuses on the performance deficits experienced in dementia (Martyr et al., 2012; Fauth et al., 2013; Toots et al., 2016). However, a burgeoning body of work is attending to steps that set up the performance of an activity. Some research discusses formulating an intention in the first place and planning the steps of the activity before its execution (Bier et al., 2013), whilst other research discusses the initiative (Teunisse and Derix, 1997; Voigt-Radloff et al., 2012; Giebel et al., 2017b), which is similar to the aforementioned. It is important to distinguish between these different elements of an activity, as people might be impaired on one, but able to complete the other, as research has indicated (Voigt-Radloff et al., 2012). In this case, it is valuable to take account of the element that the $\mathrm{PwD}$ is still able to complete, and continue engaging the $\mathrm{PwD}$ on this level. Particularly, in clinical practice, assessing both the initiative and performance of an activity is a frequent part of the general evaluation process, for which a specific tool, the Interview for Deteriorations in Daily Living Activities in Dementia (IDDD) (Teunisse et al., 1991), is used. In a pilot study employing a revised version of this tool, problems initiating some activities, such as engaging in hobbies, were linked to lower QoL in PwD (Giebel et al., 2016a). In order to further explore comprehensively how initiating everyday activities contributes to wellbeing however, a larger sample size is required.

There can be different reasons why $\mathrm{PwD}$ might struggle at initiating and performing everyday activities. Whilst the performance is strongly linked to factors such as cognition (Moheb et al., 2017), physical limitations (den Ouden et al., 2012), or environmental limitations (Gitlin et al., 2005), the reasons behind lacking the initiative to engage in an activity have been little explored. There might be other factors contributing to deficits in this area of functioning, which differ from those affecting their performance. Thus, distinguishing between the initiative and performance is important when exploring their effects on the well-being of those affected.

The aim of this cross-sectional study was to explore how deficits in the initiative and performance of IADLs in mild dementia were associated with PwD and carer well-being. Living well with dementia is a major objective of dementia care (DH, 2009), and understanding how initiative and performance deficits contribute to well-being in the early stages of the condition focuses on a so far mostly neglected aspect of everyday functioning. This knowledge could help target dementia care better and could help in the development of psychosocial interventions with the objective of improving and maintaining a good QoL early on. Therefore, only data from mild dementia cases were explored in this study, to provide information on possible support to people at the stage where most activities can still be performed. With a paucity of evidence on the relationship between individual activities and well-being and carer burden, for this exploratory study, it was hypothesised more generally that improved independence on activities was related to reduced carer burden and improved $\mathrm{PwD}$ and carer well-being (Beerens et al., 2013; Fauth et al., 2016; Reed et al., 2016).

\section{Method}

Participants and recruitment

Informal carers of $\mathrm{PwD}$ living in the community were recruited to this study. They had to be aged 18 or above and have been caring for their family member 
on a regular basis. The person they cared for had to have an official definitive diagnosis of dementia, the type of which was not considered an exclusion criterion. Carers were recruited via 10 National Health Service Trusts across England and via JoinDementiaResearch, a national research register for $\mathrm{PwD}$, carers, and healthy volunteers wishing to participate in dementia research. Staff within the Trusts handed out or mailed out questionnaires to interested and eligible carers. Completed questionnaires were returned to the research team via freepost. Additionally, the research team attended six carer support groups in the North West of England, where carers completed questionnaires. Prior to completing the questionnaire, carers provided their written informed consent to participate in the study.

The Bristol NRES Committee South West approved the study.

\section{Materials}

The revised Interview for Deteriorations in Daily Living Activities in Dementia 2 (R-IDDD2) (Giebel et al., 2017a) differentiates between the initiative and performance of 17 and 20 activities, respectively. Each activity can be rated from ' 0 ' (never lacking motivation/never any difficulties) to '4' (always lacking motivation/always difficulties). Each performance activity can be further explored if an activity is rated as impaired (so rated from ' 1 ' to ' 4 '), by having three sub-activities for each of the 20 activities. The R-IDDD2 is a valid tool in assessing everyday functioning (Giebel et al., 2017a).

Carer QoL was measured using the Adult Carer Quality of Life (AC-QoL) questionnaire (Elwick et al., 2010). The measure includes 40 items which can be rated from 'never' to 'always' and has a maximum score of 120. Higher scores indicate better QoL. Carer distress was measured using the General Health Questionnaire 12 (GHQ-12) (Goldberg and Williams, 1988). Twelve items are rated on a four-point Likert scale comparing recent psychological distress to usual levels. A maximum score of 36 can be obtained, with higher scores indicating increased distress. People with dementia QoL was measured using the Quality of Life in Alzheimer's Disease (QoL-AD) (Logsdon et al., 1999). Each of the 13 items, including family, financial situation, and life as a whole, can be rated from ' 0 ' (poor) to '4' (excellent). The R-IDDD2 also included one question about what carers consider to be the most distressing problem with everyday activities. This was entered into a free-text box.

\section{Data analysis}

Data were analysed using SPSS Version 22. PwD were categorised for their severity of dementia (mild, moderate, severe) based on a previous large European data set of community-dwelling PwD. The European data set on the RightTimePlaceCare programme (Verbeek et al., 2012) contained global cognitive scores through the Standardised Mini-Mental State Examination (S-MMSE), as well as data on the length of symptom presentation and number of carer hours per day undertaking ADLs, IADLs, and general supervision. Thus, $\mathrm{PwD}$ in the European data set were categorised according to S-MMSE scores, into mild (24-20), moderate (19-10), and severe dementia (9-0). Next, the data were used to calculate average symptom duration, hours of ADL care and IADL care, and hours of supervision for each of the three stages. These means and approximate cutoffs were utilised in the present study in order to categorise the PwD into the three groups. Further details to the specific analyses are published elsewhere (Giebel et al., 2017b). The overall study recruited 604 carers of $\mathrm{PwD}$, of which 272 were categorised to care for someone with mild, 170 for someone with moderate, and 139 for someone with severe dementia. Twentythree cases could not be categorised due to missing data. For this analysis, only data from carers of people with mild dementia were included.

Demographic characteristics and qualitative accounts of the most burdensome IADL were analysed using frequency analysis. Correlation analysis was employed to assess the relationships between individual IADLs on the initiative and performance scale with the GHQ-12, the AC-QoL, and the QoL-AD. To compare the proportion of $\mathrm{PwD}$ impaired for those with low and high distress and well-being, the median of the GHQ12, the AC-QoL, and the QoL-AD were calculated, and the groups were split based on the median. $\mathrm{Chi}^{2}$ tests were used to compare the proportion of severely impaired $\mathrm{PwD}$ based on distress and well-being groupings.

\section{Results}

In total, data from 272 carers of people with mild dementia were included in this analysis (see Table 1). The majority of PwD had Alzheimer's disease, followed by vascular dementia and mixed dementia. Carers were on average $67(+/-12)$ years old, primarily female, the spouses or child of the $\mathrm{PwD}$ and in the majority of cases lived with the PwD. Most 
Table 1 Demographic characteristics and well-being scores

\begin{tabular}{|c|c|}
\hline & $\begin{array}{l}\text { Mild dementia } \\
\qquad N=272\end{array}$ \\
\hline \multicolumn{2}{|l|}{$N(\%)$} \\
\hline \multicolumn{2}{|l|}{ PwD gender } \\
\hline Female & $140(51.5)$ \\
\hline \multicolumn{2}{|l|}{ Carer gender } \\
\hline Female & $181(66.5)$ \\
\hline \multicolumn{2}{|l|}{ PwD ethnicity } \\
\hline White Caucasian & $162(95.9)$ \\
\hline \multicolumn{2}{|l|}{ Carer ethnicity } \\
\hline White Caucasian & 164 (96.5) \\
\hline \multicolumn{2}{|l|}{ Relationship to PwD } \\
\hline Spouse & $183(67.3)$ \\
\hline Child & $76(27.9)$ \\
\hline Grandchild & $2(0.7)$ \\
\hline Other relative & $5(1.8)$ \\
\hline Friend/Neighbour & $6(2.2)$ \\
\hline \multicolumn{2}{|l|}{ Dementia type } \\
\hline$A D$ & $152(55.9)$ \\
\hline $\mathrm{VaD}$ & $38(14.0)$ \\
\hline Mixed & $36(13.2)$ \\
\hline SD & $1(0.4)$ \\
\hline FTD & $6(2.2)$ \\
\hline DLB & 9 (3.3) \\
\hline $\mathrm{PD}$ & $4(1.5)$ \\
\hline Unknown & $26(9.6)$ \\
\hline Sole carer & $214(78.7)$ \\
\hline Living with PwD & 192 (70.6) \\
\hline \multicolumn{2}{|l|}{ Mean (SD) } \\
\hline PwD age & 77 (9) \\
\hline Carer age & 67 (12) \\
\hline Years of symptoms & $3.1(1.8)$ \\
\hline Years of care & $1.9(1.4)$ \\
\hline Hours/day ADL caring & $0.7(1.2)$ \\
\hline Hours/day IADL caring & $0.9(0.8)$ \\
\hline Hours/day spent supervising PwD & $1.0(0.9)$ \\
\hline GHQ-12 & $13.8(5.6)$ \\
\hline AC-QoL & $72.3(18.7)$ \\
\hline QoL-AD & $31.2(6.6)$ \\
\hline
\end{tabular}

AD, Alzheimer's disease; DLB, dementia with Lewy bodies; FTD, frontotemporal dementia; PD, Parkinson's dementia; SD, semantic dementia; $\mathrm{VaD}$, vascular dementia.

carers were the sole carer for their relative with dementia. PwD were on average $77(+/-9)$ years old, roughly equally gender distributed, and had presented symptoms of dementia on average for $3.1(+/-1.8)$ years. A large proportion of carers and $\mathrm{PwD}$ was White Caucasian, with some people from ethnic minority backgrounds such as South Asian. Carers reported an average of $0.7(+/-1.2)$ hours a day spent on ADLs, $0.9(+/-0.8)$ hours a day on IADLs, and 1.0 $(+/-0.9)$ hours a day supervising the PwD with everyday activities.

Table 2 shows the bivariate correlations between initiative and performance of IADLs and GHQ-12, AC-QoL, and the QoL-AD. Deficits in the initiative of daily activities were related to higher carer distress
(GHQ-12), and with lower carer QoL (AC-QoL) and PwD QoL (QoL-AD). Initiating computer use, medication management, and driving were not associated with carer distress. Engaging in hobbies and maintaining an active social life, as well as cleaning and doing repair works, showed the highest correlations with well-being for both PwD and carers.

Deficits in the performance of IADLs were significantly correlated with increased carer distress and lower carer and PwD QoL. Driving was the only activity not associated with carer burden and showed low correlations with carer QoL. Engaging in hobbies and maintaining an active social life showed the strongest associations with well-being.

Tables 3 and 4 show variations in the proportion of PwD severely impaired at initiating and performing everyday activities by splitting the sample into those with low $(0-13)$ or high $(13+)$ carer distress, low $(0-72)$ or high $(72+)$ carer QoL, or low $(0-31)$ or high (32+) PwD QoL. For the majority of activities, significantly more PwD were impaired 'often' or 'always' on initiating or performing an activity in the group experiencing high carer distress, low carer QoL, and low PwD QoL. The greatest number of activities varied between low and high PwD QoL for their initiative and performance.

The qualitative evaluation of carer comments indicated that carers were mostly distressed by problems with monitoring the day, including keeping to appointments, $(\mathrm{N}=24)$, followed by dressing $(\mathrm{N}=17)$ and preparing a meal $(\mathrm{N}=17)$. The vast majority of carers $(\mathrm{N}=151)$ stated that they were not distressed by a specific activity or left the box blank.

\section{Discussion}

Difficulties with initiating and performing IADLs are significantly associated with reduced $\mathrm{PwD}$ and carer well-being and heightened levels of carer burden, thereby confirming the previously stated hypotheses. Focusing on individual activities offers a more comprehensive assessment that can detect variations in the relationship with well-being and consequently might aid in the targeted management of dementia. In particular, this study is amongst the first to highlight the importance of focusing on the initiative of everyday activities in order to live well with dementia.

Engaging in hobbies and maintaining an active social life were associated most strongly with both carer and PwD well-being. Data thus showed that not only difficulties in performing the activity, but also lacking the initiative to do so, are linked significantly to poorer 
Table 2 Relationship between initiating and performing activities and well-being in mild dementia

\begin{tabular}{|c|c|c|c|c|c|c|}
\hline & \multicolumn{3}{|c|}{ Initiating } & \multicolumn{3}{|c|}{ Performing } \\
\hline & GHQ12 & $A C-Q o L$ & QoL-AD & GHQ12 & $A C-Q \circ L$ & QoL-AD \\
\hline Washing oneself & $.261^{\star *}$ & $-.343^{\star \star}$ & $-.394^{\star \star}$ & $.291^{\star \star}$ & $-.249^{\star \star}$ & $-.347^{\star *}$ \\
\hline Making tea/coffee & $.179^{\star \star}$ & $-.239^{\star \star}$ & $-.315^{\star \star}$ & $.301^{\star *}$ & $-.183^{\star \star}$ & $-.240^{\star *}$ \\
\hline Dressing & $.271^{\star *}$ & $-.334^{\star *}$ & $-.373^{\star \star}$ & $.301^{\star *}$ & $-.304^{\star \star}$ & $-.363^{\star *}$ \\
\hline Brushing hair/teeth, shaving & $.253^{\star *}$ & $-.316^{\star \star}$ & $-.393^{\star *}$ & $.316^{\star *}$ & $-.283^{\star \star}$ & $-.341^{\star *}$ \\
\hline Shopping & $.191^{\star *}$ & $-.323^{\star \star}$ & $-.364^{\star \star}$ & $.220^{\star \star}$ & $-.257^{\star *}$ & $-.399^{\star \star}$ \\
\hline Using the telephone & $.150^{\star}$ & $-.312^{\star \star}$ & $-.275^{\star \star}$ & $.293^{\star *}$ & $-.361^{\star \star}$ & $-.302^{\star *}$ \\
\hline Using the computer & .099 & $-.305^{\star \star}$ & $-.380^{\star \star}$ & $.175^{\star}$ & $-.279^{\star \star}$ & $-.306^{\star \star}$ \\
\hline Preparing a cold meal & $.199^{\star \star}$ & $-.330^{\star \star}$ & $-.358^{\star \star}$ & $.259^{\star \star}$ & $-.266^{\star \star}$ & $-.309^{\star *}$ \\
\hline Preparing a hot meal & $.233^{\star \star}$ & $-.375^{\star \star}$ & $-.363^{\star \star}$ & $.257^{\star \star}$ & $-.275^{\star \star}$ & $-.221^{\star *}$ \\
\hline Cleaning house/doing repair work & $.294^{\star *}$ & $-.431^{\star \star}$ & $-.417^{\star \star}$ & $.305^{\star *}$ & $-.354^{\star \star}$ & $-.403^{\star \star}$ \\
\hline Handling finances & $.137^{*}$ & $-.283^{\star \star}$ & $-.128^{\star}$ & $.222^{\star \star}$ & $-.276^{\star \star}$ & $-.313^{\star \star}$ \\
\hline Medication management & .038 & $-.204^{\star \star}$ & $-.128^{*}$ & $.270^{\star *}$ & $-.317^{\star \star}$ & $-.382^{\star *}$ \\
\hline Driving & .115 & $-.312^{\star \star}$ & $-.371^{\star \star}$ & .121 & $-.235^{\star \star}$ & $-.331^{\star *}$ \\
\hline Taking public transport & $.195^{\star \star}$ & $-.310^{\star \star}$ & $-.413^{\star \star}$ & $.317^{\star \star}$ & $-.362^{\star \star}$ & $-.389^{\star \star}$ \\
\hline \multicolumn{7}{|l|}{ Maintaining active social life/ } \\
\hline Engaging in hobbies & $.230^{\star *}$ & $-.433^{\star \star}$ & $-.527^{\star \star}$ & $.250^{\star \star}$ & $-.413^{\star \star}$ & $-.477^{\star \star}$ \\
\hline Following familiar routes & $.280^{\star \star}$ & $-.318^{\star \star}$ & $-.314^{\star \star}$ & $.239^{\star *}$ & $-.318^{\star \star}$ & $-.358^{\star \star}$ \\
\hline Following current affairs & $.258^{\star \star}$ & $-.360^{\star \star}$ & $-.419^{\star \star}$ & $.217^{\star \star}$ & $-.315^{\star \star}$ & $-.383^{\star \star}$ \\
\hline Recognising familiar faces & & & & $.225^{\star \star}$ & $-.255^{\star \star}$ & $-.277^{\star \star}$ \\
\hline Monitoring own day & & & & $.161^{\star *}$ & $-.257^{\star \star}$ & $-.289^{\star *}$ \\
\hline Monitoring current activity & & & & $.277^{\star *}$ & $-.314^{\star *}$ & $-.341^{\star *}$ \\
\hline Total & $.284^{\star \star}$ & $-.451^{\star \star}$ & $-.488^{\star \star}$ & $.363^{\star \star}$ & $-.398^{\star \star}$ & $-.453^{\star \star}$ \\
\hline
\end{tabular}

Note: Grey-shaded areas are not part of the initiative scale.

GHQ12, General Health Questionnaire 12 (carer distress); AC-QoL, Adult Carer Quality of Life scale (carer); QoL-AD, Quality of Life in Alzheimer's Disease (PwD).

${ }^{*} p<0.05$

${ }^{* *} p<0.01$

Table 3 Association between initiative impairment and carer distress and quality of life (carer and PwD)

\begin{tabular}{|c|c|c|c|c|c|c|c|c|c|}
\hline & $\begin{array}{c}{ }^{\mathrm{a} G H Q 12} \\
\text { low } \\
N=150\end{array}$ & $\begin{array}{c}\text { GHQ12 } \\
\text { high } \\
N=118\end{array}$ & $\mathrm{Sig}^{*}$ & $\begin{array}{c}{ }^{\mathrm{b}} \mathrm{AC}-\mathrm{Q} \text { oL } \\
\text { low } \\
N=119\end{array}$ & $\begin{array}{c}\text { AC-QoL } \\
\text { high } \\
N=117\end{array}$ & Sig & $\begin{array}{c}{ }^{c} \text { QoL-AD } \\
\text { low } \\
N=136\end{array}$ & $\begin{array}{c}\begin{array}{c}\text { QoL-AD } \\
\text { high }\end{array} \\
N=128\end{array}$ & Sig \\
\hline Washing oneself & $14(9.3)$ & $28(23.9)$ & $p \leq .001$ & $52(43.7)$ & $10(8.5)$ & $p \leq .001$ & $32(23.5)$ & $8(6.3)$ & $p<.001$ \\
\hline Making tea/coffee & $26(17.6)$ & $29(24.8)$ & - & $27(23.1)$ & $22(18.8)$ & - & $36(26.8)$ & $18(14.1)$ & $p<.01$ \\
\hline Dressing & $10(6.8)$ & 16 (13.9) & $p<.05$ & $14(11.8)$ & $9(7.9)$ & - & 19 (14.4) & $6(4.8)$ & $p<.01$ \\
\hline Brushing hair/teeth, shaving & $18(12.0)$ & $21(18.4)$ & - & $25(21.2)$ & $10(8.6)$ & $p<.01$ & 31 (23.2) & $8(6.3)$ & $p<.001$ \\
\hline Shopping & $53(36.3)$ & $55(47.5)$ & $p<.05$ & $58(49.6)$ & $35(30.5)$ & $p<.01$ & $69(51.8)$ & $37(29.4)$ & $p<.001$ \\
\hline Using the telephone & 59 (39.6) & $63(53.9)$ & $p<.05$ & $66(55.5)$ & 39 (33.7) & $p \leq .001$ & $77(57.0)$ & $43(33.6)$ & $p<.001$ \\
\hline Using the computer & 76 (69.1) & 69 (76.7) & - & $74(81.3)$ & $51(61.4)$ & $p<.01$ & $86(86.8)$ & $55(56.7)$ & $p<.001$ \\
\hline Preparing a cold meal & 46 (31.5) & 47 (41.6) & - & $51(44.0)$ & 30 (26.6) & $p<.01$ & $62(48.0)$ & $30(23.6)$ & $p<.001$ \\
\hline Preparing a hot meal & $82(56.2)$ & 74 (66.6) & $p<.05$ & $80(69.6)$ & $57(50.0)$ & $p<.01$ & $92(71.3)$ & $61(48.4)$ & $p<.001$ \\
\hline Cleaning house/doing repair work & $62(41.9)$ & $67(59.3)$ & $p<.01$ & $72(62.1)$ & $42(36.2)$ & $p<.001$ & $83(63.4)$ & $43(33.9)$ & $p<.001$ \\
\hline Handling finances & $105(72.9)$ & $90(79.6)$ & - & $94(82.5)$ & $76(67.3)$ & $p<.01$ & $110(84.0)$ & $83(67.5)$ & $p<.01$ \\
\hline Medication management & 65 (43.6) & 67 (59.3) & $p<.01$ & $66(56.9)$ & 48 (41.4) & $p<.05$ & 79 (59.9) & $50(39.4)$ & $p \leq .001$ \\
\hline Driving & $63(61.8)$ & $53(66.3)$ & - & $63(73.3)$ & $42(56.8)$ & $p<.05$ & 73 (80.2) & $42(47.7)$ & $p<.001$ \\
\hline $\begin{array}{l}\text { Taking public transport } \\
\text { Maintaining active social life/ }\end{array}$ & $66(50.0)$ & $65(63.1)$ & $p<.05$ & 71 (68.3) & $46(46.0)$ & $p \leq .001$ & $82(70.1)$ & $46(40.7)$ & $p<.001$ \\
\hline Engaging in hobbies & $64(43.2)$ & $62(52.6)$ & - & $69(58.0)$ & $41(35.0)$ & $p<.001$ & $87(64.0)$ & $37(29.1)$ & $p<.001$ \\
\hline Following familiar routes & $31(21.3)$ & 46 (40.7) & $p \leq .001$ & $42(36.2)$ & $25(22.0)$ & $p<.05$ & $53(40.4)$ & $21(16.8)$ & $p<.001$ \\
\hline Following current affairs & $56(38.0)$ & $66(56.4)$ & $p<.01$ & $66(55.5)$ & $43(37.1)$ & $p<.01$ & $80(59.3)$ & $41(32.5)$ & $p<.001$ \\
\hline
\end{tabular}

Table shows $N(\%)$ of $\mathrm{PwD}$ impaired 'often' or 'always'.

${ }^{*}$ Chi-square test of association.

$\mathrm{a}=$ General Health Questionnaire 12 (carer distress); b = Adult Carer Quality of Life scale (carer); c = Quality of Life in Alzheimer's Disease (PwD).

well-being, thereby confirming and further elaborating on evidence reporting the relationship between activities of daily living and QoL (Farina et al., 2017; Miguel et al., 2016). A previous pilot investigation into the relationship between initiative and well-being with 20 carers of people with mild dementia corroborates this finding now on a much larger scale (Giebel et al., 2016a). Indeed, the present study provides strong 
Table 4 Variations in performance impairment based on high or low carer distress, QoL, and person with dementia QoL

\begin{tabular}{|c|c|c|c|c|c|c|c|c|c|}
\hline & $\begin{array}{c}{ }^{\mathrm{a} G H Q 12} \\
\text { low } \\
N=147\end{array}$ & $\begin{array}{c}\text { GHQ12 } \\
\text { high } \\
N=116\end{array}$ & $\mathrm{Sig}^{*}$ & $\begin{array}{c}{ }^{\text {b AC-QoL }} \\
\text { low } \\
N=118\end{array}$ & $\begin{array}{c}\text { AC-QoL } \\
\text { high } \\
N=115\end{array}$ & $\mathrm{Sig}^{*}$ & $\begin{array}{c}{ }^{\circ} \text { QoL- } \\
\text { AD } \\
\text { low } \\
N=132\end{array}$ & $\begin{array}{c}\text { QoL-AD } \\
\text { high } \\
N=128\end{array}$ & $\mathrm{Sig}^{*}$ \\
\hline Washing oneself & $19(13.3)$ & $29(25.4)$ & $p \leq .01$ & $28(24.1)$ & $15(13.1)$ & $p<.05$ & $34(26.1)$ & $13(10.4)$ & $p \leq .001$ \\
\hline Making tea/coffee & $19(13.1)$ & $35(30.9)$ & $p<.001$ & $30(25.8)$ & 20 (17.3) & - & $36(28.3)$ & 17 (13.3) & $p<.01$ \\
\hline Dressing & 18 (12.5) & $31(26.7)$ & $p<.01$ & $31(25.5)$ & $14(12.4)$ & $p<.01$ & $35(26.7)$ & $13(10.4)$ & $p \leq .001$ \\
\hline Brushing hair/teeth, shaving & $13(9.3)$ & $25(21.9)$ & $p<.01$ & $25(21.6)$ & $10(9.0)$ & $p<.01$ & $26(20.2)$ & $12(9.6)$ & $p<.05$ \\
\hline Shopping & 43 (32.3) & $42(42.8)$ & - & $46(45.6)$ & $33(30.0)$ & $p<.05$ & $55(48.3)$ & $29(25.0)$ & $p<.001$ \\
\hline Using the telephone & $41(28.7)$ & $59(50.9)$ & $p<.001$ & $56(48.7)$ & 34 (29.6) & $p<.01$ & $64(48.9)$ & $35(28.0)$ & $p<.001$ \\
\hline Using the computer & $58(63.1)$ & $59(73.8)$ & - & $57(76.0)$ & $48(60.1)$ & $p<.05$ & $66(80.5)$ & $48(55.2)$ & $p<.001$ \\
\hline Preparing a cold meal & $24(17.3)$ & $31(28.5)$ & $p<.05$ & $30(27.3)$ & $20(18.1)$ & - & $34(28.1)$ & 19 (15.3) & $p<.05$ \\
\hline Preparing a hot meal & $43(33.3)$ & 44 (54.6) & $p \leq .001$ & $51(50.5)$ & 27 (35.2) & $p<.05$ & 56 (49.6) & $39(25.5)$ & $p<.05$ \\
\hline Cleaning house/doing repair work & 39 (27.9) & $52(48.6)$ & $p \leq .001$ & $52(47.3)$ & $31(28.2)$ & $p<.01$ & $61(50.0)$ & 29 (23.4) & $p<.001$ \\
\hline Handling finances & $73(51.8)$ & $74(65.5)$ & $p<.05$ & $77(67.0)$ & $58(52.2)$ & $p<.05$ & 88 (69.3) & 59 (47.6) & $p<.01$ \\
\hline Medication management & $54(39.4)$ & $69(61.6)$ & $p<.001$ & 68 (61.2) & $44(38.0)$ & $p<.001$ & 77 (61.2) & $44(36.3)$ & $p<.001$ \\
\hline Driving & $52(59.8)$ & $44(60.2)$ & - & $47(64.4)$ & $43(61.40)$ & - & $52(71.2)$ & $45(52.3)$ & $p<.05$ \\
\hline $\begin{array}{l}\text { Taking public transport } \\
\text { Maintaining active social }\end{array}$ & $46(42.2)$ & $48(54.0)$ & - & $56(63.0)$ & $35(39.7)$ & $p<.01$ & $65(63.7)$ & $30(31.9)$ & $p<.001$ \\
\hline life/Engaging in hobbies & $65(45.7)$ & $72(62.6)$ & $p<.01$ & 78 (67.8) & 44 (38.9) & $p<.001$ & $88(68.8)$ & $47(37.4)$ & $p<.001$ \\
\hline Following familiar routes & 36 (25.2) & $46(41.1)$ & $p<.01$ & 48 (42.1) & $26(23.0)$ & $p<.01$ & 54 (42.6) & 28 (22.4) & $p<.001$ \\
\hline Following current affairs & $67(45.8)$ & $74(64.3)$ & $p<.01$ & 73 (62.4) & $51(45.2)$ & $p<.01$ & $86(65.1)$ & $53(42.0)$ & $p<.001$ \\
\hline Recognising familiar faces & 18 (12.2) & $17(15.0)$ & - & $18(15.60)$ & $15(13.0)$ & - & $22(16.8)$ & $13(10.3)$ & - \\
\hline Monitoring own day & $56(38.4)$ & $61(53.1)$ & $p<.05$ & $60(50.9)$ & $47(41.3)$ & - & $72(54.4)$ & $43(34.1)$ & $p \leq .001$ \\
\hline Monitoring current activity & 59 (41.0) & $63(54.8)$ & $p<.05$ & 65 (55.5) & $43(37.7)$ & $p<.01$ & $74(56.5)$ & $46(36.8)$ & $p \leq .001$ \\
\hline
\end{tabular}

Table shows proportion of PwD impaired 'often' or 'always'.

${ }^{*}$ Chi-square test of association.

$\mathrm{a}=$ General Health Questionnaire 12 (carer distress); b = Adult Carer Quality of Life scale (carer); c = Quality of Life in Alzheimer's Disease (PwD).

additional evidence that engaging in hobbies/ maintaining an active social life is a vital element to well-being. Whilst the pilot investigation showed that initiative deficits in this activity were associated only with PwD QoL, the present analysis demonstrates that this activity is the most strongly related to QoL of PwD and carers, and well-being. Whilst causation has not been shown within this study, in order to improve well-being for both the $\mathrm{PwD}$ and the carer, there could be two possible options that integrate social activities. On the one hand, psychosocial interventions might need to specifically target the individual hobbies of a PwD, both in their initiative by raising levels of motivation and in their performance, by providing structured training and support to perform the activity. An alternative or additional option might be for the $\mathrm{PwD}$, and carer, to participate in dementia-specific social groups or activities. One such example is 'Coffee, Cake, \& Culture', an art initiative by the Whitworth Art Gallery in Manchester to appreciate art and engage with peers in a friendly environment (Roe et al., 2014). Other options are singing groups (Osman et al., 2014) or community-based football groups specifically for PwD (Carone et al., 2016), all of which have been found to improve well-being. Hence, encouraging participation in previously enjoyed hobbies and other social activities appears to be a vital contributor to well-being, which might require a greater level of attention than other IADLs, especially because engaging in social activities and maintaining social relationships contributes to a reduced risk of developing dementia, amongst others (Marioni et al., 2015).

It is unclear why carer distress as measured on the GHQ-12 was not found to be significantly associated with engaging in hobbies and maintaining an active social life. However, there are other activities which were only found to be significantly associated with carer and PwD well-being, but not carer distress, e.g. driving and handling finances. One possible reason could be that lacking the initiative to engage in an active social life only affects the well-being of a carer, whilst it is not linked to being distressed or burdened. Findings suggest that needing reminders to initiate tasks such as preparing a hot meal or getting dressed are related to carer burden, as they presumably cause a carer to provide many prompts on a daily/weekly basis. In addition, lacking the initiative to adhere to medication is equally associated with carer burden, an important everyday task which PwD often not adhere to (Arlt et al., 2008). In contrast, engaging in hobbies is not a necessary part of a person's everyday life and might therefore require fewer reminders, or hobbies might get neglected altogether so that no reminders might be required. This suggests that care interventions focusing on maintaining or improving social functions should weigh up the benefits for patient and carer well-being and carer distress. 
When asked directly about the most distressing everyday activity, the majority of carers were either not distressed by one, or stated a behavioural problem, such as aggression or repetition as the most disturbing symptom, rather than an IADL or ADL. Specifically, monitoring the day, followed by dressing, were regarded as the most distressing activities. Contrary to the quantitative findings, few carers $(N=13)$ stated that difficulties with initiating or performing hobbies or engaging in social activities were most distressing. All carers were aware of the spectrum of IADLs, which could therefore not explain why carers' qualitative responses varied from the quantitative results. This suggests that some carers might not realise that one or more activities affect their well-being, as is supported by the large number of carers who did not provide an answer to this question.

The initiative of some activities was not related to well-being. Computer use and driving were amongst these and, indeed, were also the two activities which carers frequently left blank and noted as not applicable, as the PwD was never able to do these. Considering that these two, very technical, daily activities were managed by the smallest number of participants in the first place, it might not be surprising to see that lacking the initiative for either has no statistical impact on carer burden. Problems initiating medication management on the other hand might not affect carer burden because of the ready availability of assistive technology (AT) for this IADL. Medication dispensers with alarms are frequently used in dementia care (Gibson et al., 2016), with AT in general being found to be of greater benefit to carers (Gibson et al., 2015). This suggests that deficits in the initiative of some IADLs could be relatively easily addressed with the use of AT, in providing reminders and thus effective triggers (Giebel et al., 2017a), which would reduce the responsibilities and burden placed on the carer.

Overall, the associations between initiative and performance and PwD QoL were stronger than those with carer well-being. Considering that carers rated all types of well-being, it might be the case that carers rated PwD well-being to be more severely affected than their own well-being. Indeed, previous research corroborates variations in ratings between proxies and PwD (Sands et al., 2004). There are also other factors that might have influenced proxy ratings of the PwD' QoL, including levels of carer burden, carer health, and age of the PwD (Orgeta et al., 2015). Depressive symptomatology might also have contributed to low initiative ratings in $\mathrm{PwD}$, as depression is found to be linked to everyday functioning in general (Payne et al., 1998). Future research should explore how PwD would rate their own levels of initiative and performance, and how this is associated with well-being.

Findings can have important implications for effective care management and the design of nonpharmaceutical interventions. As outlined in the Medical Research Council guidelines (2005), developing effective interventions involves focusing on theory as well as evidence, which can then be translated preferably with the input of patients, carers, and clinicians into an intervention. Findings suggest that addressing individual activities might have a greater impact on improving PwD QoL, whilst still providing benefits to carers by potentially improving well-being and reducing carer burden. In the intervention design process, it is therefore important to clarify the motivations behind participating in an intervention (Giebel et al., 2016b), whether this is targeted at improving PwD QoL or carer burden for example.

There are some limitations to this study. One potential limitation is the categorisation of people into mild dementia. However, this categorisation was based on an extensive statistical procedure involving a large European data set, of which findings from the overall sample, including people in the mild, moderate, and severe stages of dementia, have been published elsewhere (Giebel et al., 2017b). Furthermore, statistically we performed a large number of Chi-square tests and correlation analyses. We did not adjust for this with a Bonferroni correction, because the significance cut-off value would decrease to such a degree that the Type I error would be reduced, but the Type II error would be increased by a large amount.

\section{Conclusions}

In conclusion, living well with dementia involves being aware of how individual daily activities affect the well-being of PwD and their carers, and how these can be addressed more directly. Social activities were found to be particularly strongly linked to well-being in mild dementia, suggesting the need for greater accessibility to dementia-based social groups. From the data, it could be further implied that AT might be a feasible way to reduce carer distress, as evidenced for medication management. Findings could thus have direct implications for dementia care practice, by providing more social opportunities for $\mathrm{PwD}$ or dyads, and possibly by integrating AT to a greater extent in everyday life. Future research ought to explore whether AT can indeed result in reduced carer distress for a variety of IADLs. 


\section{Description of authors' roles}

C.G. designed the study, collected and analysed the data, and drafted the article. C.G. and C.S. rated the dementia cases for their severity. C.S. commented on versions of the paper and approved the final draft.

\section{Conflict of interest}

None.

Key points

- Lacking the initiative to engage in everyday activities is associated with poor carer and people with dementia quality of life and increased carer burden.

- Quality of life, as opposed to carer burden, is strongly associated with initiation.

- Carer management should consider the associations with well-being when addressing individual activities.

\section{Acknowledgments}

This article presents independent research supported by the National Institute for Health Research (NIHR), under its Programme Grants for Applied Research programme (Grant Reference Number: DTC-RP-PG0311-12003), and forms part of the doctoral thesis of CG, and was funded by the University of Manchester's School of Nursing, Midwifery and Social Work Pump Priming Award 2015. We wish to thank all carers for taking part in this research, and staff at the following NHS trusts for their support in recruiting participants: Southend University Hospital; Black Country Partnership; Surrey and Borders Partnership; Lincolnshire Partnership; Derbyshire Community Health Services; Lancashire Care; Leicestershire Partnership; Southern Health; and North Essex. We also wish to thank Division 4 Greater Manchester NIHR Clinical Research Network for recruiting participants to this study through Manchester Mental Health and Social Care NHS Trust. Our thanks also extend to the JoinDementiaResearch Network as well as the following carer support groups for allowing us to recruit carers through their networks: Crossgates, Later Life Living, Life Story Network, Together Dementia, LMCP Care Link, and Bury Carers Centre.

\section{References}

Alzheimer's Disease International. 2015. World Alzheimer report 2015: the global impact of dementia. London: Alzheimer Disease International

Andersen CK, Wittrup-Jensen KU, Lolk A, Andersen K, Kragh-Sorensen P. 2004. Ability to perform activities of daily living is the main factor affecting quality of life in patients with dementia. Health Qual Life Outcomes 2: 52-58.

Arlt S, Lindner R, Rosler A, von Renteln-Kruse W. 2008. Adherence to medication in patients with dementia. Drugs Aging 25(12): 1033-1047.

Beerens HC, Zwakhalen SMG, Verbeek H, et al. 2013. Factors associated with quality of life of people with dementia in long-term care facilities: a systematic review. Int $J$ Nurs Stud 50(9): 1259-1270.

Beerens HC, De Boer B, Zwakhalen SMG, et al. 2016. The association between aspects of daily life and quality of life of people with dementia living in long-term care facilities: a momentary assessment study. Int Psychogeriatr. https://doi.org/ $10.1017 /$ S1041610216000466.

Bier N, Bottari C, Hudon C, et al. 2013. The impact of semantic dementia on everyday actions: evidence from an ecological study. J Int Neuropsychol Soc 19(02): 162-172.

Birren J, Lubben J, Rowe J. 1991. The Concept of Measurement of Quality of Life in the Frail Elderly. Academic Press: San Diego.

Carone L, Tischler V, Dening T. 2016. Football and dementia: a qualitative investigation of a community based sports group for men with early onset dementia. Dementia 15(6): 1358-1376. https://doi.org/10.1177/1471301214560239.

Den Ouden MEM, Schuurmans MJ, Arts IEMA, van der Schouw YT. 2012. Association between physical performance characteristics and independence in activities of daily living in middle-aged and elderly men. Geriatr Gerontol Int 13(2): 274-280.

Department of Health. 2009. Living Well with Dementia: A National Dementia Strategy. Department of Health: London.

Elwick H, Joseph S, Becker S, Becker F. 2010. Manual for the Adult Carer Quality of Life Questionnaire (AC-QoL). The Princess Royal Trust for Carers: London.

Farina N, Page TE, Daley S, et al. 2017. Factors associated with the quality of life of family carers of people with dementia: A systematic review. Alzheimer's \& Dementia. https://doi.org/10.1016/j.jalz.2016.12.010.

Fauth EB, Femia EE, Zarit SH. 2016. Resistiveness to care during assistance with activities of daily living in non-institutionalized persons with dementia: associations with informal caregivers' stress and well-being. Aging Ment Health 20(9): 888-898.

Fauth EB, Schwartz S, Tschanz JT, et al. 2013. Baseline disability in activities of daily living predicts dementia risk even after controlling for baseline global cognitive ability and depressive symptoms. Int J Ger Psychiatr 28: 597-606.

Gibson G, Newton L, Pritchard G, et al. 2016. The provision of assistive technology products and services for people with dementia in the United Kingdom. Dementia 15(4): 681-701. https://doi.org/10.1177/1471301214532643.

Gibson G, Dickinson C, Brittain K, Robinson L. 2015. The everyday use of assistive technology by people with dementia and their family carers: a qualitative study. BMC Geriatr 15: 89-98.

Giebel CM, Challis D, Montaldi D. 2016a. A revised Interview for Deteriorations in Daily Living Activities in Dementia (R-IDDD) reveals the relationship between social activities and well-being. Dementia 15(5): 1068-1081.

Giebel CM, Challis D, Hooper NM, Ferris S. 2016b. A step-by-step translation of evidence into a psychosocial intervention for everyday activities in dementia: a focus group study. Aging Ment Health. https://doi.org/10.1080/ 13607863.2016.1262819.

Giebel CM, Challis D, Montaldi D. 2017a. The newly revised Interview for Deteriorations in Daily Living Activities in Dementia (R-IDDD2): distinguishing initiative from performance at assessment. Int Psychogeriatr 29(3): 497-507.

Giebel CM, Sutcliffe C, Challis D. 2017b. Hierarchical decline of initiative and performance deficits of complex activities of daily living in dementia. $J$ Geriatr Psychiatr Neurol 30(2): 96-103.

Gitlin LN, Hauck WW, Dennis MP, Winter L. 2005. Maintenance of effects of the home environmental skill-building program for family caregivers and individuals with Alzheimer's disease and related disorders. J Gerontol A Biol Sci Med Sci 60(3): 368-374.

Goldberg D, Williams P. 1988. A User's Guide to the General Health Questionnaire. NFER-Nelson: Windsor, UK.

Logsdon RG, Gibbons LE, McCurry SM, Teri L. 1999. Quality of life in Alzheimer's disease: Patient and caregiver reports. J Ment Health Aging 5(1): 21-32.

Marioni RE, Proust-Lima C, Amieva H, et al. 2015. Social activity, cognitive decline and dementia risk: a 20-year prospective cohort study. BMC Public Health 15: 1089-1096.

Martyr A, Clare L, Nelis SM, et al. 2012. Verbal fluency and awareness of functional deficits in early-stage dementia. Clin Neuropsychol 26(3): 501-519.

Miguel S, Alvira M, Farre M, et al. 2016. Quality of life and associated factors in older people with dementia living in long-term institutional care and home care. European Geriatr Med 7(4): 346-351. 
Mioshi E, Foxe D, Leslie F, et al. 2013. The impact of dementia severity on caregiver burden in frontotemporal dementia and Alzheimer's disease. Alz Dis Assoc Disord 27(1): 68-73.

Moheb N, Mendez MF, Kremen SA, Teng E. 2017. Executive dysfunction and behavioral symptoms are associated with deficits in instrumental activities of daily living in frontotemporal dementia. Dement Geriatr Cogn Disord 43(1-2): 89-99.

Monaci L, Morris RG. 2012. Neuropsychological screening performance and the association with activities of daily living and instrumental activities of daily living in dementia: baseline and 18- to 24-month follow-up. Int J Geriatr Psychiatr 27(2): 197-204.

Orgeta V, Orrell M, Hounsome B, Woods B. 2015. Self and carer perspectives of quality of life in dementia using the QoL-AD. Int J Geriatr Psychiatr 30(1): 97-104.

Osman SE, Tischler V, Schneider J. 2014. 'Singing for the Brain': a qualitative study exploring the health and well-being benefits of singing for people with dementia and their carers. Dementia. https://doi.org/10.1177/1471301214556291.

Payne JL et al. 1998. Relationship of cognitive and functional impairment to depressive features in Alzheimer's disease and other dementias. J Neuropsychiatr Clin Neurosci 10: 440-447.

Prince M, Knapp M, Guerchet M, et al. 2014. Dementia UK: Update. London: Alzheimer's Society.

Sands LP, Ferreira P, Stewart AL, Brod M, Yaffe K. 2004. What explains differences between dementia patients' and their caregivers' ratings of patients' quality of life? Am J Geriatr Psychiatry 12(3): 272-280.
Sutcliffe CL, Giebel CM, Jolley D, Challis D. 2016. Experience of burden in carers of people with dementia at the margins of long-term care. Int J Geriatr Psychiatr 31(2): 101-108. Reed C, Belger M, Vellas B, Andrews JS. 2016. Identifying factors of activities of daily living important for cost and caregiver outcomes in Alzheimer's disease. Int Psychogeriatr 28(2): 247-259.

Roe B, McCormick S, Lucas T, et al. 2014. Coffee, Cake \& Culture: evaluation of an art for health programme for older people in the community. Dementia. https:// doi.org/10.1177/1471301214528927.

Teunisse S, Derix MM. 1997. The interview for deterioration in daily living activities in dementia: agreement between primary and secondary caregivers. Int Psychogeriatr 9(1): 155-162.

Teunisse S, Derix MMA, van Crevel H. 1991. Assessing the severity of dementia. Arch Neurol 48(3): 274-277.

Toot S, Swinson T, Devine M, Challis D, Orrell M. 2017. Causes of nursing home placement for older people with dementia: a systematic review and meta-analysis. Int Psychogeriatr 29(2): 195-208. https://doi.org/10.1017/S1041610216001654.

Toots A, Littbrand H, Lindelof N, et al. 2016. Effects of a high-intensity functional exercise program on dependence in activities of daily living and balance in older adults with dementia. J Am Geriatr Soc 64(1): 55-64.

Verbeek H, Meyer G, Leino-Kilpi H, et al. 2012. A European study investigating patterns of transition from home care towards institutional dementia care: the protocol of a RightTimePlaceCare study. BMC Public Health 12: 68.

Voigt-Radloff S, Leonhardt R, Schutzwohl M, et al. 2012. Interview for deterioration in daily living activities in dementia: construct and concurrent validity in patients with mild to moderate dementia. Int Psychogeriatr 24(3): 382-390. 